\title{
Prescriber and patient-oriented behavioural interventions to improve use of malaria rapid diagnostic tests in Tanzania: facility-based cluster randomised trial
}

Bonnie Cundill ${ }^{1 *}$, Hilda Mbakilwa², Clare IR Chandler ${ }^{3}$, George Mtove $^{4}$, Frank Mtei ${ }^{2}$, Annie Willetts ${ }^{5}$, Emily Foster ${ }^{2}$, Florida Muro ${ }^{2}$, Rahim Mwinyishehe ${ }^{4}$, Renata Mandike ${ }^{6}$, Raimos Olomi ${ }^{2}$, Christopher JM Whitty ${ }^{7}$ and Hugh Reyburn ${ }^{7}$

\begin{abstract}
Background: The increasing investment in malaria rapid diagnostic tests (RDTs) to differentiate malarial and non-malarial fevers, and an awareness of the need to improve case management of non-malarial fever, indicates an urgent need for high quality evidence on how best to improve prescribers' practices.

Methods: A three-arm stratified cluster-randomised trial was conducted in 36 primary healthcare facilities from September 2010 to March 2012 within two rural districts in northeast Tanzania where malaria transmission has been declining. Interventions were guided by formative mixed-methods research and were introduced in phases. Prescribing staff from all facilities received standard Ministry of Health RDT training. Prescribers from facilities in the health worker (HW) and health worker-patient (HWP) arms further participated in small interactive peer-group training sessions with the HWP additionally receiving clinic posters and patient leaflets. Performance feedback and motivational mobile-phone text messaging (SMS) were added to the HW and HWP arms in later phases. The primary outcome was the proportion of patients with a non-severe, non-malarial illness incorrectly prescribed a (recommended) antimalarial. Secondary outcomes investigated RDT uptake, adherence to results, and antibiotic prescribing.
\end{abstract}

Results: Standard RDT training reduced pre-trial levels of antimalarial prescribing, which was sustained throughout the trial. Both interventions significantly lowered incorrect prescribing of recommended antimalarials from 8\% $(749 / 8,942)$ in the standard training arm to $2 \%(250 / 10,118)$ in the HW arm (adjusted RD (aRD) 4\%; 95\% confidence interval (CI) $1 \%$ to $6 \% ; P=0.008)$ and $2 \%(184 / 10,163)$ in the HWP arm (aRD 4\%; $95 \% \mathrm{Cl} 1 \%$ to $6 \% ; P=0.005)$. Small group training and SMS were incrementally effective. There was also a significant reduction in the prescribing of antimalarials to RDT-negatives but no effect on RDT-positives receiving an ACT. Antibiotic prescribing was significantly lower in the HWP arm but had increased in all arms compared with pre-trial levels.

Conclusions: Small group training with SMS was associated with an incremental and sustained improvement in prescriber adherence to RDT results and reducing over-prescribing of antimalarials to close to zero. These interventions may become increasingly important to cope with the wider range of diagnostic and treatment options for patients with acute febrile illness in Africa.

Trial registration: ClinicalTrials.gov (\#NCT01292707) 29 January 2011.

Keywords: Malaria, Cluster-randomised, Rapid diagnostic test, ACT, Behavioural interventions, Primary care, Tanzania

\footnotetext{
* Correspondence: bonnie.cundill@|shtm.ac.uk

${ }^{1}$ Faculty of Epidemiology and Population Health, London School of Hygiene and Tropical Medicine, Keppel St, London WCIE 7HT, UK

Full list of author information is available at the end of the article
} 


\section{Background}

Acute febrile illness is the commonest presentation in Africa, and overdiagnosis of malaria in febrile patients in Africa and Asia is a major public health problem [1-3].Over the last decade the introduction of the relatively expensive artemisinin-based combination therapies (ACT) and the subsequent appearance of artemisinin resistance in south-east Asia have driven the need to rationalise the overuse of antimalarial drugs in Africa and Asia [4]. In addition the recent decline in malaria transmission in many areas of Africa has led to increasing awareness that 'presumptive treatment for malaria' is often associated with neglect of non-malarial causes of fever [5,6]. The availability of affordable and reliable rapid diagnostic tests for malaria (RDTs), comparable in price and often more accurate than a standard malaria blood slide, has provided a potentially important tool to address these problems. In 2010 the 'WHO Guidelines for Malaria Diagnosis and Treatment' replaced the policy of presumptive treatment for malaria in children with no obvious alternative cause of fever with a policy of recommending parasitological confirmation in all patients with suspected malaria before treatment wherever possible and restricting antimalarial treatment to parasitepositive patients $[7,8]$.

Providing new tools does not however necessarily change practice. A large scale-up in the deployment of malaria RDTs by national malaria control programmes from less than 200,000 in 2005 to more than 108 million in 2012 has been undertaken [9]. However, increased use of parasitological tests of malaria to guide treatment often fails to achieve its objective due to lack of infrastructural and social support for denying antimalarial drugs, leading to a persistent preference among prescribers for a diagnosis of malaria, even in the face of a negative test result. In 1997 increased availability of blood slide microscopy in Zambia had little effect due to the tendency to prescribe antimalarial treatment on clinical grounds ('presumptive treatment') or to slide-negative patients and almost a decade later a Tanzanian study found that half of test-negative outpatients provided with RDTs and basic training were prescribed an antimalarial drug and this did not vary whether tested by RDT or blood slide [10,11]. A number of more recent studies have shown large variability in adherence to current guidelines for malaria diagnosis in both Africa and Asia, but the overall problem of preference for a diagnosis of malaria has generally prevailed [12-16]. This reduces both the clinical effectiveness and cost-effectiveness of RDTs [17], and leads to persistent overdiagnosis of malaria. Getting misdiagnosis of febrile illness as malaria close to zero should lead to improved case management and allow routine data to be used for public health. It will also be essential in areas where local elimination is the aim.
The increasing investment in RDTs and awareness of the need to improve case management of non-malarial fever indicate an urgent need for high quality evidence on how best to improve prescribers' use of RDTs and adherence to the results. The reasons for overprescription of antimalarials even when test results are negative are complex, and depend on prescriber perceptions including of patient expectations [18]. We therefore hypothesised that interventions aimed at patient perceptions would reinforce those targeting prescribers. However, despite the large number of training interventions with prescribers in Africa, there is no strong evidence to guide the most effective format, content and techniques to change prescribing practices [19]. Few, if any, interventions have been tested that explicitly aim to intervene on the perception of prescribers of what patients want in terms of prescription in these settings. We thus conducted the Targeting Artemisinin Combination Trial (TACT), a stratified cluster-randomised trial in primary care facilities in north east Tanzania of prescriber and patient-oriented behavioural interventions to improve adherence to national and WHO malaria diagnosis and treatment guidelines. The design of interventions was guided by formative mixed-methods research, to understand the existing scenario of malaria diagnosis and antimalarial use within facilities in the trial area, and the need for simplicity and affordability if trial results are to be scaleable [19]. This formative research took an 'evidence-based' approach to the intervention design comprising five key stages: 1) focus group discussions and in-depth interviews with health workers and community members to understand the existing scenario of malaria diagnosis and antimalarial use; 2) a review of evidence and engagement in behaviour change theory to guide choice of intervention strategies; 3) a structured project workshop to bring together findings from previous stages into a draft outline of intervention activities and key messages; 4) designing the intervention materials; and 5) piloting and pre-testing the intervention materials.

\section{Methods}

\section{Study design and participants}

Between September 2010 and March 2012 we conducted a three-arm stratified cluster randomised trial among 36 facilities (clusters) within two predominately rural districts, Muheza in the Tanga region and Moshi Rural in the Kilimanjaro region, in northeast Tanzania. Malaria transmission is moderate in Muheza and low in Moshi, and has been declining over the past decade [20]. Adherence to RDT and slide results has been shown to be very poor in previous studies even after basic training [11,21]. Due to the differing transmission intensities and previous research findings we expected that the primary 
outcome would vary considerably across the clusters within and between the districts. We therefore stratified both by district and the proportion of all consultations that were diagnosed with malaria in the previous year, as reported in the routine Health Management Information System (MTUHA book). Within each district facilities were ranked according to the proportion of malaria consultations and split into two equal categories, giving a total of four strata (Figure 1).

Primary care facilities registered with the District Medical Office were eligible for inclusion if: they were in receipt of supplies of recommended antimalarial drugs from the Ministry of Health; qualified for RDT supply from the Government and agreed to exclusive use of RDT for routine diagnosis of suspected malaria; were accessible by four-wheel drive vehicle throughout the year; and facility data confirmed that there were more than 500 malaria diagnoses in the previous year. All prescribers employed at the facilities at any point during the trial duration were eligible to receive the intervention. On average, more than $75 \%$ of health workers at the study facilities were regular prescribers. Consenting patients who had not been referred to the next level of care were also eligible for inclusion. The nature and purpose of the trial was explained to participants and written informed consent was sought from heads of the facilities and prescribers, prior to randomisation. Participants were informed of the trial through leaflets and posters displayed in facilities' waiting areas and health workers obtained verbal consent from patients, or carers for patients under the age of 15 , to participate prior to their consultation.

\section{Selection of facilities, randomisation and blinding}

Within each stratum, facilities were selected at random from those eligible using a computer-generated programme. Randomisation to the three trial arms was conducted within each stratum through a process of restricted (constrained) randomisation, to ensure marginal balance across the strata and study groups on covariates expected to be important correlates of the primary outcome [22]. Balance was considered achieved when: the number of health workers differed by no more than three between the study arms; number of prescribers differed by no more than two; the two mission facilities were in different arms; and the proportion of all consultations that were diagnosed with malaria in the previous year differed by less than $10 \%$. The validity of the randomisation

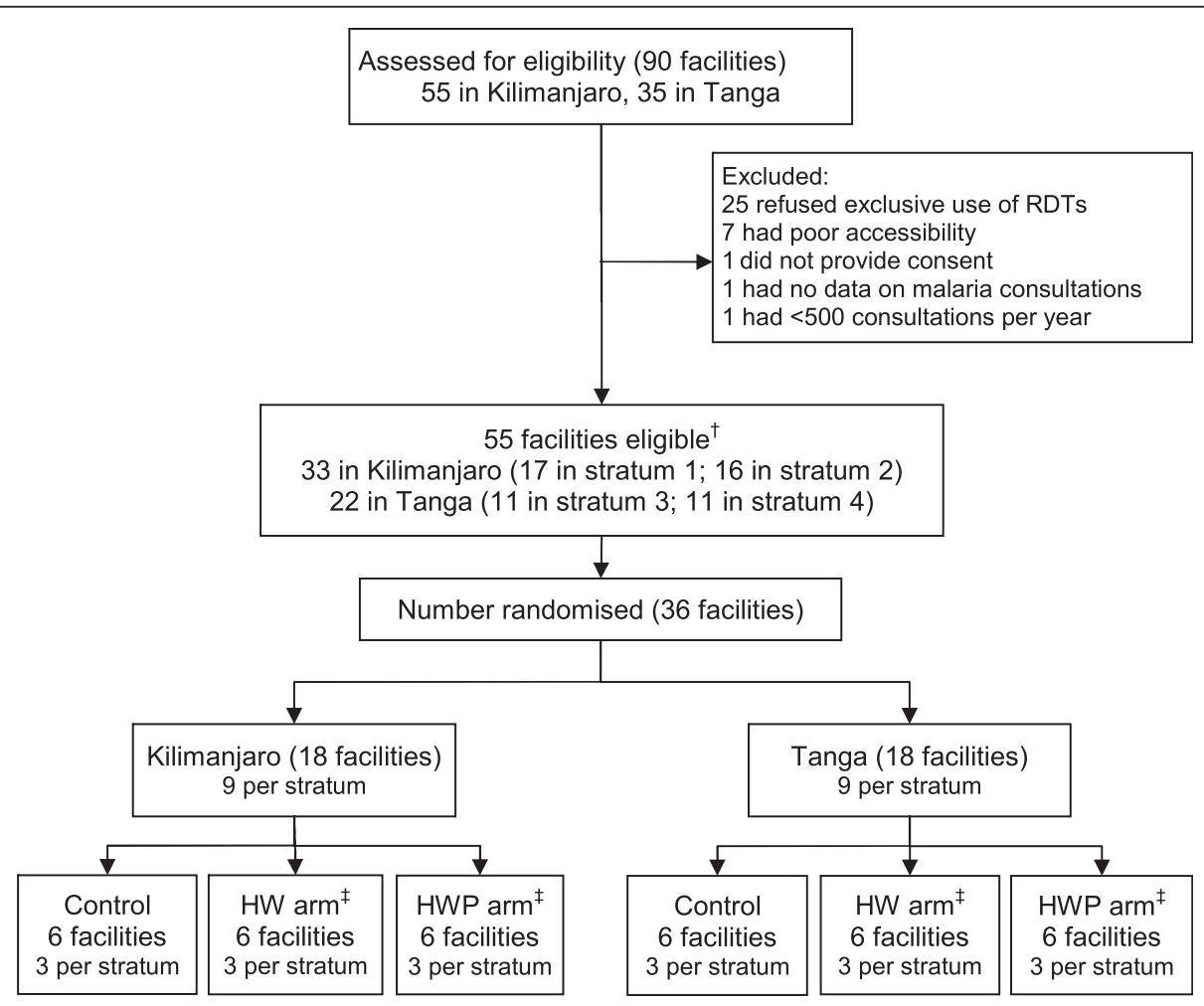

Figure 1 Flow of facilities through assessment of eligibility, selection and randomization. ${ }^{\dagger}$ Strata 1 and 3 had fewer malaria cases in Kilimanjaro and Tanga, respectively, while strata 2 and 4 had more malaria cases when dividing the districts into two equal categories based on the proportion of malaria consultations. Equal numbers of facilities were randomized to each arm within strata. ${ }^{\ddagger}$ Control represents the standard RDT training arm. HW represents the health worker intervention arm. HWP represents the health worker and patient-oriented intervention arm. 
was assessed by examining the proportion of times triplets of clusters were allocated to the same study arm for under- and over-representation [23-25]. Selection and randomisation of facilities was conducted by the trial statistician who was not involved in the delivery of the intervention or assessment of the study outcomes using a program written in $\mathrm{R}$ statistical software version 2.13.0 (R Foundation for Statistical Computing, Vienna, Austria). We were not consistently able to blind patients, those delivering the interventions, or assessors of the study outcomes; however assessors were rotated through study arms every three months.

\section{Interventions}

The three arms of the trial were: 1) the standard training arm (termed control); 2) the health worker (HW) intervention arm; and 3) the health worker plus patientoriented (HWP) intervention arm. The final multi-level intervention targeting individual prescribers at the trial facilities as well as their interaction with patients included: small group workshops, feedback and motivational mobile-phone text messages (SMS) to all prescribers in the intervention facilities and patient leaflets and clinic posters to the HWP facilities (Table 1, Figure 2). The rationale and details of the behavioural interventions in each trial arm are detailed elsewhere [19] but described in brief below.

Baseline data were collected from all randomised facilities between September 2010 and January 2011. Following baseline data collection each consenting prescriber from the facilities in all arms of the trial attended the
Ministry of Health's existing two-day RDT training (approximately 30 to 50 participants), delivered by approved National Malaria Control Programme (NMCP) trainers [26]. This was followed by a visit to the facilities by research staff when RDTs and associated supplies were provided. This defined the beginning of the evaluation period of the trial in February 2011. All facilities were also visited four to six weekly by a trained research assistant who provided essential supplies including RDTs, recorded dates of any stock outs of RDTs and $\mathrm{ACT}$, and observed prescribers' performance in RDTs if they were treating patients who required testing during the visit. Prescribers use of RDTs was checked for following the test procedure as presented in the standard training. No other aspect of the consultation was documented or commented upon.

In addition to the standard RDT training prescribers from facilities randomised to the HW and HWP arms received further training through three interactive workshops four to six weeks later. These were of approximately two hours with a small group of four to eight prescribing colleagues from neighbouring facilities, led by a group moderator from the project. Workshops followed three pre-written modules based on three stages of a change process: preparing, experimenting and consolidating prescribing change. The first module aimed to sensitise prescribers to the TACT trial and the rationale for the change in policy for management of febrile illness in order that individuals and peers consider if and how to change practice. The second module aimed at providing prescribers with confidence when

Table 1 Timelines for intervention implementation, outcome data collection and evaluation

\begin{tabular}{|c|c|c|}
\hline $\begin{array}{l}\text { Intervention component/ } \\
\text { Data collection period }\end{array}$ & Description of the evaluation period & Timescales \\
\hline Standard RDT training & & 18 Jan to 28 Jan 2011 \\
\hline RDT supply & & 22 Feb 2011 to 31 Jan 2012 \\
\hline \multirow[t]{2}{*}{ Evaluation period 1} & \multirow{2}{*}{$\begin{array}{l}\text { Commenced following standard RDT training and RDT supply until the } \\
\text { start of the interactive workshops }\end{array}$} & 4 to 6 weeks \\
\hline & & 24 Feb to 3 April 2011 \\
\hline Interactive workshops & & 4 April to 18 May 2011 \\
\hline \multirow[t]{2}{*}{ Evaluation period 2} & \multirow{2}{*}{$\begin{array}{l}\text { Commenced once the interactive workshops had been completed until } \\
\text { the start of the feedback SMS }\end{array}$} & approx 20 weeks \\
\hline & & 19 May to 9 Oct 2011 \\
\hline Feedback SMS & & 10 Oct 2011 to 12 Mar 2012 \\
\hline \multirow[t]{2}{*}{ Evaluation period 3} & \multirow{2}{*}{$\begin{array}{l}\text { Commenced when the feedback SMS were introduced until the start } \\
\text { of the motivational SMS }\end{array}$} & 13 weeks \\
\hline & & 10 Oct 2011 to 8 Jan 2012 \\
\hline Motivational SMS & & 9 Jan to 12 Mar 2012 \\
\hline \multirow[t]{2}{*}{ Evaluation period 4} & \multirow{2}{*}{$\begin{array}{l}\text { Commenced once the motivational SMS were introduced until the final } \\
\text { exit survey }\end{array}$} & 6 to 9 weeks \\
\hline & & 9 Jan to 12 Mar 2012 \\
\hline Final exit survey & & 22 Feb to 12 Mar 2012 \\
\hline Overall evaluation period & Commenced following the introduction of the RDTs until the final exit survey & 22 Feb 2011 to 12 Mar 2012 \\
\hline
\end{tabular}




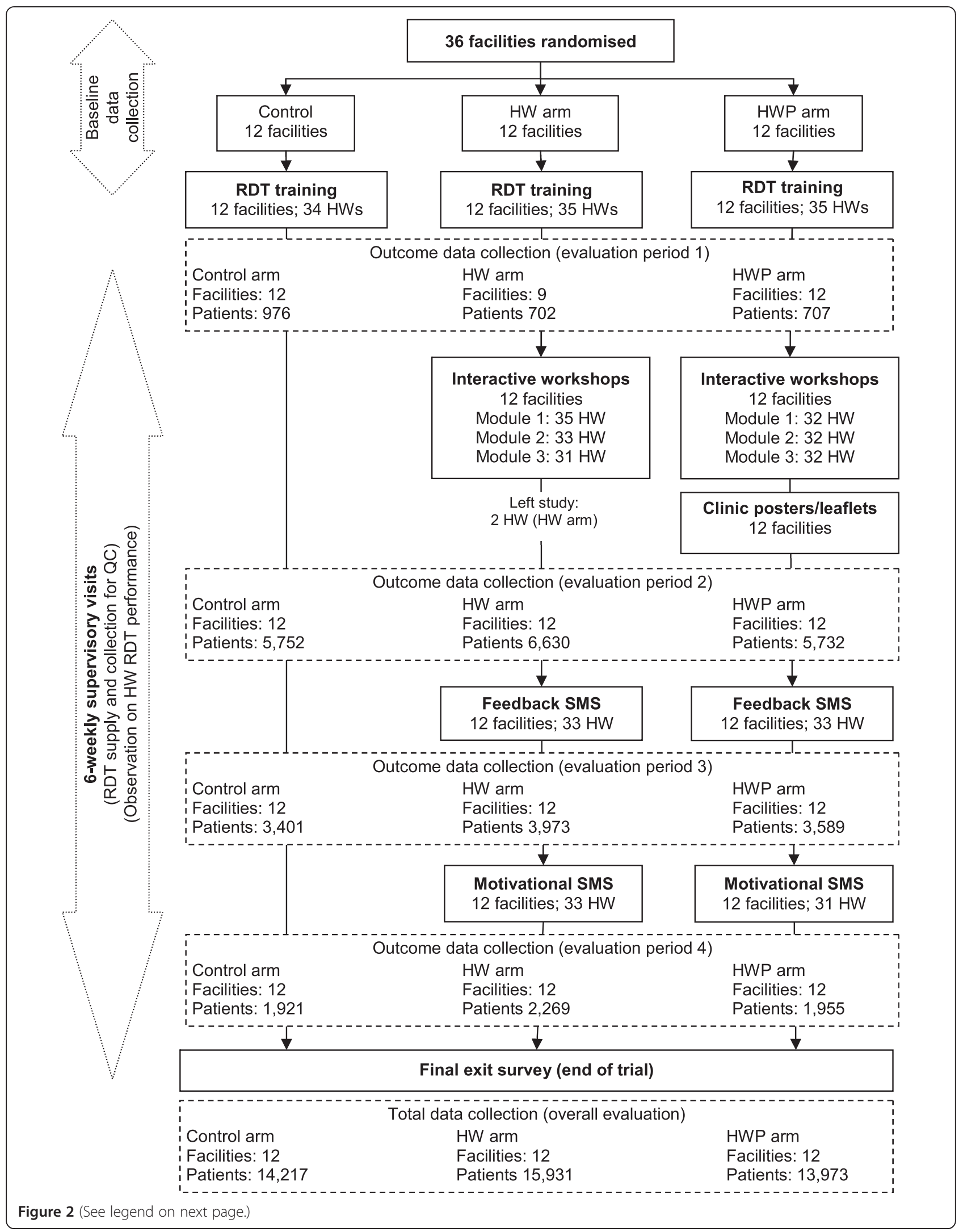


(See figure on previous page.)

Figure 2 Flow of facilities, health workers (prescribers) and patients through different stages of the intervention and evaluation. The outcome data collection periods include eligible patients presenting at the facilities between the intervention implementation activities. For example, evaluation period 1 commences after the standard RDT training and initial RDT supply until the start of the intervention training. See Table 1 for further details on timing of intervention implementation and evaluation. The total data collection is based on all eligible patients presenting at the facilities following the standard RDT training until the final exit survey. It, therefore, includes patients presenting during the intervention implementation activities which were excluded in the outcome data collection periods. RDT, rapid diagnostic test.

using RDTs, in particular the capacity to communicate effectively, including negotiating with patients who disagree with the prescribed clinical management. The final module was aimed at sustaining the change in practice by using challenging role-plays to practice integration of RDTs and demonstrate the capacity to problem solve a RDT logistical challenge. The groups were encouraged to share experiences and to work together to identify solutions.

Prescribers in the HWP arm additionally received a supply of patient leaflets and clinic posters designed to influence prescribers through encouraging demand for RDTs and adherence to results as best practice by patients, following action research with community members and several rounds of pretesting. These were to be displayed and distributed at the facilities for the duration of the trial. Patients were not asked or expected to make any particular response to the prescriber, although the prescriber could use the leaflets to explain their decision making if they wished to do so.

Data on the implementation of the training were collected through self-filled questionnaires for participants and trainers, self-reflection and feedback from trainers, observations of training modules, and in-depth interviews.

Approximately five months after the interactive workshops until the end of the trial, prescribing staff in both intervention arms were sent a series of SMS to reinforce the aims of the workshops; namely, to build prescribers' motivation, skills and confidence to implement the strategy of RDTs in the realities of their own practice. Initially they provided a feedback summary to prescribers of their previous month's performance on the use of RDTs (proportion of eligible patients who were tested) and treatment prescribed based on RDT results (proportion of patients with a negative test treated with an antimalarial drug). These were then followed by motivational SMS twice a day over a 15-day period with a message on malaria case management alternated with a motivational proverb [27].

Implementation and evaluation of the intervention activities lasted 13 months and the end of the trial was defined by a one-week recording of RDT and blood slides for all consenting patients exiting the trial facilities.

\section{Outcomes}

The primary outcome was the proportion of patients with a non-severe, non-malarial illness being incorrectly prescribed a (recommended) antimalarial in a new consultation. A non-severe illness was defined as an illness not resulting in referral to the next level of care. Nonmalarial was defined as a negative RDT result or no history of fever in the previous two days of a new consultation or an obvious alternate diagnosis (soft tissue, ear or urine infection). A recommended antimalarial was quinine for children under two months old, quinine or artemether-lumefantrine (ALu - the first-line ACT in Tanzania) for women of childbearing age (15 to 45 years), and ALu for all others. Secondary outcomes examined in more depth the use of RDTs and adherence to test results as well as treatment with antibiotics.

Outcomes were measured through an intervieweradministered survey administered to all eligible and consenting patients (or caretakers) exiting the trial facilities. The survey was conducted on randomly varied two days blocks per week by survey staff recruited from the nearby population using criteria of literacy and availability and given two days of training on site. All patients exiting a consultation were briefly interviewed to determine if they had suspected malaria and if so whether they had been prescribed an antimalarial or antibiotic and if they had been tested by a RDT. Prescribers were also asked to record the same information as the exit survey as part of routine Health Management Information System (MTUHA book). These records acted as a secondary source to supplement the exit survey.

Assuming that at least $30 \%$ of patients with a nonmalarial illness are treated with an antimalarial in the control arm, and a coefficient of variation between facilities within stratum of 0.25 , we calculated that 12 facilities per arm and 8 non-malarial patients per facility per week would give $80 \%$ power to detect an absolute reduction from $30 \%$ to $20 \%$ in the primary outcome, at the $5 \%$ significance level [28].

RDTs $\left(\right.$ Paracheck $^{\text {тM }}$ ) were subject to national quality control measures as follows: 10 tests from each 1,000 tests supplied within a single batch were be sent for testing against known histidine-rich protein II (HRP-2) solutions maintained by the Ifakara Health Research and Development Centre in Tanzania. Tests were stored at 
recommended temperatures (that is, above freezing and $<40^{\circ} \mathrm{C}$ ) monitored by high and low reading thermometers. At supervision visits a single test was taken from each 25 -test box and tested against whole blood containing 2,000 parasites per microlitre. Testnegative RDTs against this standard were replaced by a box of new tests. At the end of the trial the RDTs and blood slides from all patients were used to compare the accuracy of RDT against research-quality slide reading. Paracheck is recommended by the NMCP in Tanzania and has been shown to reach high levels of accuracy in East Africa [29,30].

\section{Statistical methods}

All data were double-entered using Microsoft Access 2007 (Microsoft Inc., Redmond, WA, USA) and analysed using STATA version 12.0 (STATA Corporation, College Station, TX, USA). Analysis was by intention-to-treat and took into account between-facility variations in treatment according to guidelines using methods suitable for stratified cluster randomised trials with fewer than 20 clusters per arm [22].

For each outcome, the risk difference (RD) in each intervention arm relative to the control was computed from the mean risks across facilities in each arm and stratum. An overall estimate of the RD was calculated as the weighted average of the stratum-specific RDs. The weights were proportional to the number of facilities per stratum for comparisons where there were even numbers of facilities allocated to the study arms within each stratum, or inversely proportional to the stratumspecific variances in cases with uneven number of facilities. Corresponding 95\% confidence intervals (CI) were obtained and formal hypothesis testing (at the 5\% significance level) was assessed by carrying out a stratified t-test on the RD. Adjustment for covariates was made by fitting a logistic regression model using data on individuals, and including terms for stratum and the covariates of interest. Expected numbers with the outcome were computed, and compared with the observed values to provide difference-residuals for each facility. The above methods for estimating the RDs, 95\% CIs and hypothesis testing were calculated as before with the residuals replacing facility-specific risks.

\section{Ethics and trial registration}

The study was approved by the Ethical Review Boards of the National Institute for Medical Research in Tanzania (NIMRlHQ/R.8cNol. 11/24) and the London School of Hygiene and Tropical Medicine (\#5877). The trial was prospectively registered with ClinicalTrials.gov (Identifier \# NCT01292707). An independent data safety monitoring board monitored the trial and approved the statistical analysis plan.

\section{Results}

Of the 55 eligible facilities, 36 were selected and randomised (12 per arm) and all are included in the analysis of the primary outcomes. A total of 44,121 eligible patients, 14,217 in the control arm, 15,931 in the HW arm, and 13,973 in the HWP arm, provided consent to participate in the study from the beginning of the trial in February 2011 until the end of the trial in March 2012 and are included in the analysis (Figures 1 and 2). All eligible patients presenting at the facilities were included in the evaluation regardless of whether the health worker they saw during the consultation was a prescriber who received training as part of the trial.

\section{Implementation of the intervention}

All facilities received the intervention package that they were randomised to. Prescribers from all facilities received the standard RDT training and the additional prescriber training in the HW and HWP arms. Each facility was represented by, on average, three prescribers (range two to five) at the standard (baseline) RDT training and three prescribers (range one to five) at each of the interactive workshop modules. Training materials were delivered as planned and well received. In the HWP arm all facilities were provided with clinic posters and patient leaflets. Observations of prescriber performance $(n=143)$ were conducted in all facilities, except one in the HWP arm, and showed good adherence $(>90 \%)$ with RDT procedures (such as RDTs only opened immediately before use and RDT negative declared after 15 minutes) throughout the duration of the evaluation period.

At least half of the facilities, six $(50 \%)$ in the control arm, seven (58\%) in the HW arm and six (50\%) in the HWP arm, recorded a stock-out of RDTs at any time during the trial. ACT stock-outs at least once during the study period were experienced by six (50\%) facilities in the control arm, five (42\%) in the HW arm, and eight (67\%) in the HWP arm. The median duration of RDT stock-outs was 20 days (range 1 to 28 days) and 41 days (range 1 to 83 days) for initial ACT stock-outs.

\section{Characteristics of the study population}

The stratification and restricted randomisation were shown to have provided comparable study arms that were generally similar in their characteristics (Tables 2 and 3), but with some exceptions in the proportion of patients presenting with fever or history of fever, and the prescribing of antimalarials and antibiotics.

Impact on treatment of patients with non-malarial illness A breakdown of the observed treatment of patients with a non-malarial illness is presented in Figure 3. Just under one-third of eligible patients attending facilities in the control $(8,942 / 14,217(63 \%))$ and HW 
Table 2 Characteristics of the facilities and prescribers in the study

Characteristics Control

Control HW arm HWP arm

FACILITY (CLUSTER) LEVEL

\begin{tabular}{|c|c|c|c|}
\hline & $\mathrm{N}_{\mathrm{c}}=12^{\mathrm{a}}$ & $N_{c}=12$ & $N_{c}=12$ \\
\hline Number of health workers per facility (median, range) & $4(2$ to 13$)$ & $4(2$ to 11$)$ & $4(2$ to 7$)$ \\
\hline$\%$ of health workers who are regular prescribers (median, range) & $80 \%(15$ to $100 \%)$ & $100 \%$ (20 to 100\%) & $75 \%$ (29 to $100 \%)$ \\
\hline \multicolumn{4}{|l|}{ Facility type } \\
\hline Government & $12(100 \%)$ & $11(92 \%)$ & $11(92 \%)$ \\
\hline Mission & $0(0 \%)$ & $1(8 \%)$ & $1(8 \%)$ \\
\hline \multicolumn{4}{|l|}{$\%$ Consultations diagnosed with malaria per year ${ }^{\mathbf{b}}$ (mean, SD) } \\
\hline$<5$ years of age & $37 \%(17 \%)$ & $34 \%(17 \%)$ & $34 \%(20 \%)$ \\
\hline$\geq 5$ years of age & $32 \%(13 \%)$ & $32 \%(14 \%)$ & $33 \%(19 \%)$ \\
\hline \multicolumn{4}{|l|}{$\%$ Consultations treated with ${ }^{\mathrm{c}}:($ mean, SD) } \\
\hline AM & $52 \%(16 \%)$ & $48 \%(20 \%)$ & $40 \%(21 \%)$ \\
\hline Recommended $\mathrm{AM}^{\mathbf{d}}$ & $46 \%(15 \%)$ & $41 \%(20 \%)$ & $31 \%(20 \%)$ \\
\hline Antibiotics & $64 \%(15 \%)$ & $67 \%(11 \%)$ & $62 \%(10 \%)$ \\
\hline \multicolumn{4}{|l|}{$\%$ Consultations presenting with fever treated with ${ }^{c}:$ (mean, SD) } \\
\hline Antimalarial (AM) & $68 \%(20 \%)$ & $67 \%(27 \%)$ & $63 \%(29 \%)$ \\
\hline Recommended $\mathrm{AM}^{\mathbf{d}}$ & $61 \%(19 \%)$ & $58 \%(26 \%)$ & $50 \%(29 \%)$ \\
\hline Antibiotics & $63 \%(17 \%)$ & $66 \%(13 \%)$ & $58 \%(15 \%)$ \\
\hline \multicolumn{4}{|l|}{$\%$ Consultations presenting without fever treated with ${ }^{c}:$ (mean, SD) } \\
\hline Antimalarial (AM) & $15 \%(12 \%)$ & $15 \%(14 \%)$ & $7 \%(8 \%)$ \\
\hline Recommended $\mathrm{AM}^{\mathbf{d}}$ & $12 \%(12 \%)$ & $12 \%(13 \%)$ & $4 \%(3 \%)$ \\
\hline Antibiotics & $70 \%(14 \%)$ & $70 \%(16 \%)$ & $69 \%(8 \%)$ \\
\hline \multicolumn{4}{|l|}{ Provision of malaria training materials } \\
\hline Posters & $8(67 \%)$ & $9(75 \%)$ & $7(58 \%)$ \\
\hline Books & $9(75 \%)$ & $10(83 \%)$ & $9(75 \%)$ \\
\hline MoH monitoring visit in the past year & $12(100 \%)$ & $12(100 \%)$ & $11(92 \%)$ \\
\hline
\end{tabular}

PRESCRIBER LEVEL

\begin{tabular}{|c|c|c|c|}
\hline & $\mathrm{N}_{\mathrm{hw}}=35^{\mathrm{a}}$ & $\mathrm{N}_{\mathrm{hw}}=35$ & $\mathrm{~N}_{\mathrm{hw}}=35$ \\
\hline Number per facility (median, range) & $3(2$ to 4$)$ & $3(2$ to 5$)$ & $3(2$ to 4$)$ \\
\hline \multicolumn{4}{|l|}{ Age (years) $^{e}$} \\
\hline 21 to 34 & $3(9 \%)$ & $7(21 \%)$ & $6(17 \%)$ \\
\hline 35 to 44 & $8(23 \%)$ & $4(15 \%)$ & $7(20 \%)$ \\
\hline 45 to 54 & $11(31 \%)$ & $18(53 \%)$ & $16(46 \%)$ \\
\hline$\geq 55$ & $13(37 \%)$ & $4(12 \%)$ & $6(17 \%)$ \\
\hline \multicolumn{4}{|l|}{ Gender } \\
\hline Male & $8(23 \%)$ & $10(29 \%)$ & $10(29 \%)$ \\
\hline Female & $27(77 \%)$ & $25(71 \%)$ & $25(71 \%)$ \\
\hline \multicolumn{4}{|l|}{ Highest education level } \\
\hline Primary & $17(49 \%)$ & $13(37 \%)$ & $11(31 \%)$ \\
\hline Secondary & $8(23 \%)$ & $13(37 \%)$ & $12(34 \%)$ \\
\hline Higher (college, training etc.) & $10(29 \%)$ & $9(26 \%)$ & $12(34 \%)$ \\
\hline \multicolumn{4}{|l|}{ Cadre $^{e}$} \\
\hline Clinician & $12(34 \%)$ & $10(29 \%)$ & $12(34 \%)$ \\
\hline Registered nurse & $7(20 \%)$ & $9(26 \%)$ & $8(23 \%)$ \\
\hline Nursing/medical attendant & $16(46 \%)$ & $15(44 \%)$ & $15(43 \%)$ \\
\hline
\end{tabular}


Table 2 Characteristics of the facilities and prescribers in the study (Continued)

\begin{tabular}{|c|c|c|c|}
\hline \multicolumn{4}{|l|}{ Length of time at facility ${ }^{e}$} \\
\hline 1 to 5 years & $14(45 \%)$ & $15(48 \%)$ & $16(47 \%)$ \\
\hline 5 to 10 years & $6(19 \%)$ & $4(13 \%)$ & $3(9 \%)$ \\
\hline More than 10 years & $11(35 \%)$ & $12(39 \%)$ & $15(48 \%)$ \\
\hline \multicolumn{4}{|l|}{ Training in past 3 years ${ }^{f}$} \\
\hline Integrated logistics system (ILS) & $10(29 \%)$ & $12(34 \%)$ & $9(26 \%)$ \\
\hline $\mathrm{IMCl}$ & $9(27 \%)$ & $10(32 \%)$ & $13(41 \%)$ \\
\hline Malaria (not specific) & $3(9 \%)$ & $4(11 \%)$ & $2(6 \%)$ \\
\hline
\end{tabular}

${ }^{a} \mathrm{~N}_{\mathrm{c}}$ represents the number of clusters (facilities); $\mathrm{N}_{\mathrm{hw}}$ represents the number of prescribers present at the facilities who consented to participate in the study; any new prescribers throughout the study duration who consented to participate were also included. ${ }^{b}$ Mean (SD: standard deviation) proportion of consultations diagnosed with malaria. Based on information available 2007 to 2009. 'New consultation of a non-severe illness. Fever defined as history of fever in the past two days. ${ }^{\mathbf{d}}$ Recommended AM defined as Quinine for children weighing less than $5 \mathrm{~kg}$ (assuming all children over two months of age will weigh $>5 \mathrm{~kg}$ ), ALu or quinine for women of childbearing age (age 15 to 45 years inclusive), ALu for all others. ${ }^{e}$ Age and cadre is missing for one prescriber in the HW arm. Time at facility missing for four prescribers in the control and HW arms and one prescriber in the HWP arm. ILS is a mobile health alert and reporting system designed to increase the visibility of logistics data and improve product availability. IMCI = integrated management of childhood illness. IMCl training missing for two prescribers in the control arm, four in HW arm, and three in HWP arm. Numbers and percentages are presented unless stated otherwise. Percentages may not add to 100 due to rounding.

$\operatorname{arm}(10,118 / 15,931(63 \%))$, and three-quarters in the HWP arm $(10,163 / 13,973(73 \%))$ were non-malarial. Of these, the percentage being incorrectly prescribed a recommended antimalarial in a new consultation was $8 \%$ in the control, $2 \%$ in the HW arm, and $2 \%$ in the HWP arm.
Compared with standard RDT training, there was strong evidence that both interventions significantly lowered the prescribing of a recommended antimalarial, even after adjusting for study design and differences observed at baseline (Table 4). The adjusted risk difference (aRD) showed

Table 3 Characteristics of patients included in the evaluation, by arm

\begin{tabular}{|c|c|c|c|}
\hline Characteristics & $\begin{array}{l}\text { Control } \\
N_{p}=14,217^{a}\end{array}$ & $\begin{array}{l}H W \text { arm } \\
N_{p}=15,931\end{array}$ & $\begin{array}{l}\text { HWP arm } \\
N_{p}=13,973\end{array}$ \\
\hline Number per facility (median, range) & 1227 (477 to 2112) & 1325 (295 to 2275$)$ & 1233 (560 to 1825$)$ \\
\hline \multicolumn{4}{|l|}{ Age (years) } \\
\hline$<5$ & $5290(37 \%)$ & $6144(39 \%)$ & $4671(33 \%)$ \\
\hline 5 to 15 & $3053(21 \%)$ & $3320(21 \%)$ & $3149(22 \%)$ \\
\hline$>15$ & $5874(41 \%)$ & $6467(41 \%)$ & $6153(44 \%)$ \\
\hline \multicolumn{4}{|l|}{ Gender } \\
\hline Male & $6308(44 \%)$ & $6810(43 \%)$ & $6128(44 \%)$ \\
\hline Female & $7909(56 \%)$ & $9121(57 \%)$ & $7845(56 \%)$ \\
\hline \multicolumn{4}{|l|}{ Presented with fever } \\
\hline No & $4876(34 \%)$ & $6088(38 \%)$ & $6000(43 \%)$ \\
\hline Yes & $9301(66 \%)$ & $9829(62 \%)$ & 7967 (57\%) \\
\hline \multicolumn{4}{|l|}{ Ear/Soft tissue infection } \\
\hline No & $12324(87 \%)$ & $14228(89 \%)$ & $12530(90 \%)$ \\
\hline Yes & $1883(13 \%)$ & $1690(11 \%)$ & $1436(10 \%)$ \\
\hline \multicolumn{4}{|l|}{ Wealth index } \\
\hline Poorest & $117(28 \%)$ & 149 (30\%) & $216(42 \%)$ \\
\hline Less poor & $159(37 \%)$ & 167 (33\%) & $152(30 \%)$ \\
\hline Least poor & $150(35 \%)$ & 187 (37\%) & 142 (28\%) \\
\hline
\end{tabular}

${ }^{\mathrm{a}} \mathrm{N}_{\mathrm{p}}$ represents the number of eligible patients included in the evaluation, defined as the period between the end of the RDT training and the end of the trial. Eligible patients were those with a non-severe first consultation. ${ }^{b}$ Measured only in a sample of patients followed up at home 14 days after they had visited the study facility. Generated through principle component analysis (PCA) and based on ownership of household possessions (for example, electricity, radio, mobile phone, bicycle, and car), access to utilities (for example, toilet type and source of drinking water), and housing characteristics (for example, floor type, fuel) in line with DHS Wealth Index [42] and Vyas et al. use of PCA for socio-economic status [43]. Numbers and percentages are presented unless stated otherwise. RDT, rapid diagnostic test. 


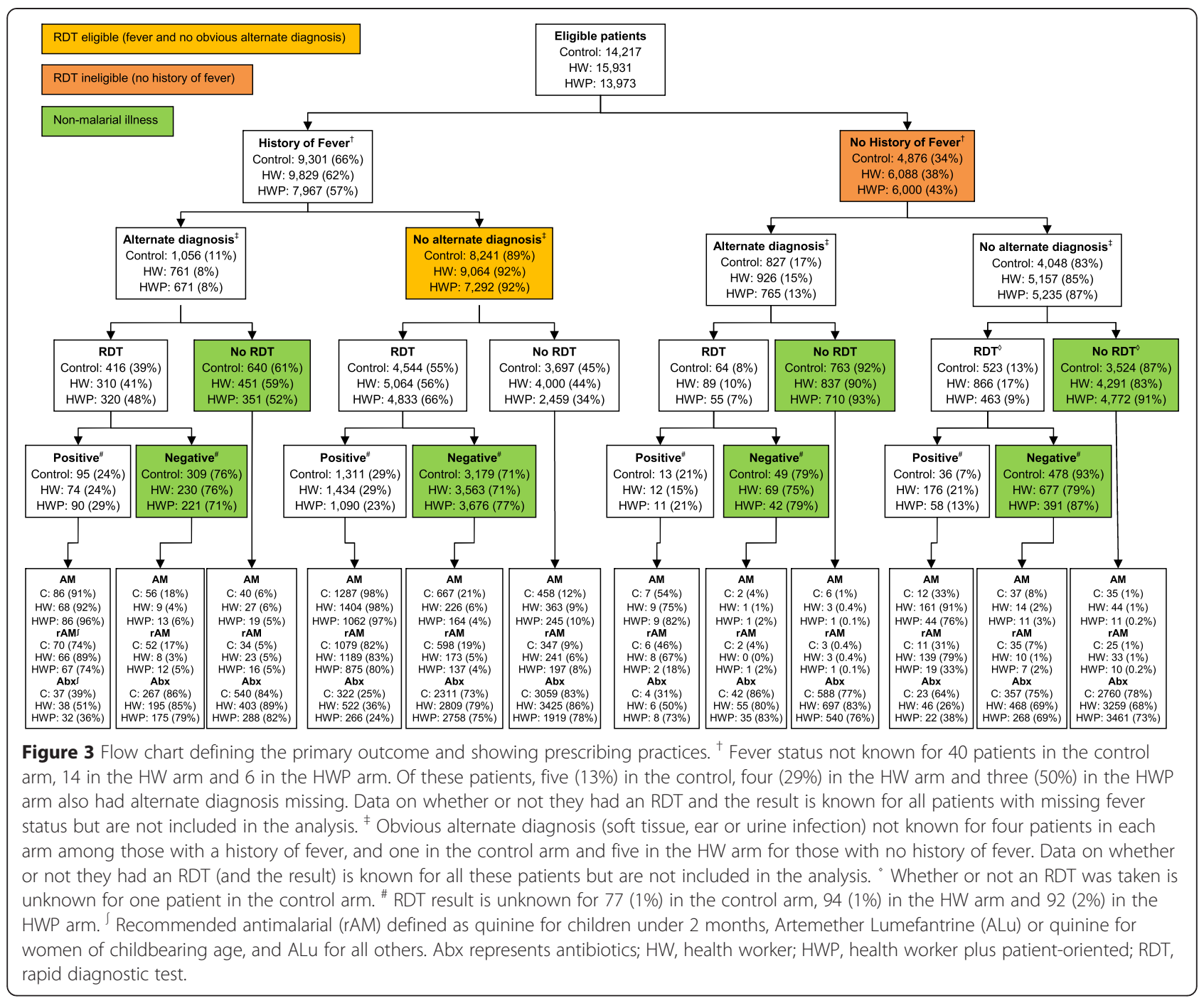

an absolute $4 \%(95 \% \mathrm{CI} 1 \%$ to $6 \% ; P=0.008)$ reduction for the intervention focusing on prescribers only ( $\mathrm{HW}$ arm), and a $4 \%$ reduction $(95 \%$ CI $1 \%$ to $6 \% ; P=0.005)$ for the intervention focusing on both the prescribers and patients (HWP arm). Similar results were observed for patients $<5$ years and $\geq 5$ years (Table 4 ), and when the analysis was restricted to those patients who 1 ) visited facilities when there was no RDT or ACT stock-outs and 2) had a consultation with a prescribing health worker who had attended the intervention training workshops (Additional files 1 and 2).

Incorrect prescribing of an antimalarial for nonmalarial illness was lower in the two intervention arms after the introduction of each component of the intervention package (Table 4). After the introduction of the standard RDT training, prescribing of a recommended antimalarial was low in all arms and there was a trend towards increased benefit of introducing feedback and motivating SMS to reinforce the training that had been received. There did not appear to be a waning of the effect of the standard RDT training.

\section{RDT uptake and adherence}

There was no evidence of a significant difference in the proportion of patients presenting with a reported fever who were tested with a RDT between the trial arms (Table 5). There was, however, evidence that RDT eligible patients (presenting with fever and no obvious alternate diagnosis) were more likely to be tested in the HWP arm (66\% tested) compared with standard training (55\% tested); aRD $18 \%(95 \%$ CI $5 \%$ to $32 \% ; P=0.01)$. Few afebrile patients were tested with an RDT, but of those who were tested up to one-fifth (21\%) were positive, including when there was an obvious alternate diagnosis (Figure 3).

The prescriber and prescriber plus patient-oriented interventions significantly reduced the proportion of RDT 
Table 4 Effect of interventions on recommended antimalarial prescribing among patients with a non-severe, non-malarial illness

\begin{tabular}{|c|c|c|c|c|c|c|c|}
\hline Evaluation category & Arm & $\begin{array}{l}\text { Number of } \\
\text { clusters }\end{array}$ & $\begin{array}{l}\text { Number of } \\
\text { patients }\end{array}$ & $\begin{array}{l}\text { Prevalence } \\
\text { number (\%) }\end{array}$ & $\begin{array}{l}\text { Crude RD } \\
(95 \% \mathrm{Cl}) \\
\end{array}$ & $\begin{array}{l}\text { Adjusted } \mathrm{RD}^{\mathrm{b}} \\
(95 \% \mathrm{Cl})\end{array}$ & $P$-value \\
\hline \multirow[t]{3}{*}{ Overall'(all ages) } & Control & 12 & 8942 & $749(8 \%)$ & 0 & 0 & \\
\hline & HW & 12 & 10118 & $250(2 \%)$ & $0.06(0.04,0.09)$ & $0.04(0.01,0.06)$ & 0.008 \\
\hline & HWP & 12 & 10163 & $184(2 \%)$ & $0.07(0.04,0.09)$ & $0.04(0.01,0.06)$ & 0.005 \\
\hline \multirow[t]{3}{*}{$<5$ years } & Control & 12 & 3139 & $392(12 \%)$ & 0 & 0 & \\
\hline & $H W$ & 12 & 3682 & $153(4 \%)$ & $0.09(0.04,0.14)$ & $0.06(0.006,0.12)$ & 0.03 \\
\hline & HWP & 12 & 3406 & $95(3 \%)$ & $0.09(0.03,0.14)$ & $0.05(0.005,0.09)$ & 0.03 \\
\hline \multirow[t]{3}{*}{$\geq 5$ years } & Control & 12 & 5803 & $357(6 \%)$ & 0 & 0 & \\
\hline & $H W$ & 12 & 6436 & $97(2 \%)$ & $0.05(0.03,0.07)$ & $0.02(0.006,0.04)$ & 0.008 \\
\hline & HWP & 12 & 6757 & $89(1 \%)$ & $0.05(0.03,0.07)$ & $0.03(0.01,0.05)$ & 0.002 \\
\hline \multicolumn{8}{|l|}{ By Evaluation period } \\
\hline \multirow{3}{*}{ Standard training - period 1 (all arms) } & Control & 12 & 656 & $48(7 \%)$ & 0 & 0 & \\
\hline & $H W$ & 9 & 449 & $3(1 \%)$ & - & - & - \\
\hline & HWP & 11 & 494 & $38(8 \%)$ & $0.001(-0.09,0.09)$ & $-0.01(-0.06,0.03)$ & 0.54 \\
\hline \multirow[t]{3}{*}{ Interactive training - period 2 (HW and HWP arms) } & Control & 12 & 3320 & $236(7 \%)$ & 0 & 0 & \\
\hline & HW & 12 & 3791 & $135(4 \%)$ & $0.05(0.02,0.08)$ & $0.02(-0.001,0.05)$ & 0.06 \\
\hline & HWP & 12 & 3802 & $81(2 \%)$ & $0.05(0.02,0.09)$ & $0.03(0.003,0.05)$ & 0.03 \\
\hline \multirow[t]{3}{*}{ Feedback SMS - period 3 (HW and HWP arms) } & Control & 12 & 2392 & $215(9 \%)$ & 0 & 0 & \\
\hline & HW & 12 & 2829 & $58(2 \%)$ & $0.06(0.04,0.09)$ & $0.02(-0.001,0.05)$ & 0.06 \\
\hline & HWP & 12 & 2891 & $24(1 \%)$ & $0.07(0.04,0.10)$ & $0.02(-0.004,0.04)$ & 0.09 \\
\hline \multirow{3}{*}{$\begin{array}{l}\text { Feedback + proverb SMS - period } 4 \\
\text { (HW and HWP arms) }\end{array}$} & Control & 12 & 1297 & $106(8 \%)$ & 0 & 0 & \\
\hline & HW & 12 & 1540 & $18(1 \%)$ & $0.07(0.05,0.09)$ & $0.03(0.007,0.06)$ & 0.01 \\
\hline & HWP & 12 & 1607 & $7(0.4 \%)$ & $0.07(0.05,0.09)$ & $0.03(0.01,0.06)$ & 0.009 \\
\hline
\end{tabular}

${ }^{a}$ Adjusted for stratification, effect estimate is risk difference = control- intervention; control is standard RDT training. ${ }^{b}$ Adjusted for facility (stratum, stock-out of $\mathrm{ACT}$, provision of materials, \% fever consultations treated with antimalarial prior to the study, \% non-febrile consultations treated with antimalarial prior to the study), prescriber (age, education, time at facility) and patient (age) characteristics.

- Insufficient number of clusters or sample size per cluster to conduct a robust analysis. 'Defined as the period of evaluation from the end of the standard RDT training until the end of the trial. The between-cluster coefficient of variation was estimated as $k=0.02$ for comparison of both intervention arms with the control. $\mathrm{ACT}$, artemisinin-based combination therapies; $\mathrm{Cl}$, confidence interval; HW, health worker; HWP, health worker plus patient-oriented; RD, risk difference; RDT, rapid diagnostic test; SMS, mobile-phone text message.

negative patients receiving an antimalarial from $19 \%$ in the control to $6 \%$ in the $\mathrm{HW}$ arm (aRD $=10 \% ; 95 \% \mathrm{CI}$ $3 \%$ to $17 \% ; P=0.01$ ) and $4 \%$ in the HWP arm (aRD $=10 \%$; 95\% CI $4 \%$ to $16 \% ; P=0.002$ ). There was no evidence, however, of a significant increase in the proportion of RDT positive patients receiving an ACT in the intervention arms $(80 \%$ in the control, $83 \%$ in the HW arm (aRD $=-13 \%$; $95 \% \mathrm{CI}-45 \%$ to $19 \%$ ), and $77 \%$ in HWP arm $(\mathrm{aRD}=-4 \% ; 95 \%-25 \%$ to $17 \%))$. Similar results were observed when analysis was restricted to patients attending facilities when there were no RDT and/or ACT stock-outs (Additional file 3).

Overall, the introduction of RDTs with the intervention packages resulted in an observed decrease in the proportion of consultations prescribed any antimalarial from $48 \%$ and $40 \%$ prior to the trial (Table 2) in the HW and HWP arms, respectively, to $15 \%$ and $12 \%$ at the end of the trial (Figure 3). In the control, the corresponding figures were $52 \%$ prior to the trial and $19 \%$ at the end of the trial.

\section{Prescribing of antibiotics}

There was no evidence of a difference in the prescribing of antibiotics between the control and HW arms but there was evidence that the HWP interventions significantly reduced the proportion of patients with non-malarial illness receiving an antibiotic (aRD 0.14; 95\% CI -0.01 to 0.29 ; $P=0.06)$. Similar results were observed among RDT negative patients and those RDT eligible and ineligible (Table 5). However, compared with prior to the trial, the prescribing of antibiotics has increased across all arms. Prior to the trial the observed proportion of consultations prescribed an antibiotics was $64 \%$ in the control arm, 67\% in the HW arm and 62\% in the HWP arm (Table 2). These figures had increased to 73\%, 75\% and $70 \%$, respectively, at the end of the trial (Figure 3). 
Table 5 Effect of interventions on antimalarial prescribing, RDT use and antibiotic prescribing

\begin{tabular}{|c|c|c|c|c|c|c|}
\hline Outcome & Arm & $\begin{array}{l}\text { Number of } \\
\text { patients }\end{array}$ & $\begin{array}{l}\text { Prevalence } \\
\text { number }(\%)\end{array}$ & $\begin{array}{l}\text { Crude RD } \\
(95 \% \mathrm{Cl}) \\
\end{array}$ & $\begin{array}{l}\text { Adjusted RD } \\
(95 \% \mathrm{CI})\end{array}$ & $P$-value \\
\hline \multirow[t]{3}{*}{ Patients with fever treated with rAM } & Control & 9,231 & $2180(24 \%)$ & 0 & 0 & \\
\hline & HW & 9,752 & $1700(17 \%)$ & $0.07(0.004,0.13)$ & $0.03(-0.04,0.10)$ & 0.44 \\
\hline & HWP & 7,887 & $1304(16 \%)$ & $0.07(0.01,0.14)$ & $0.05(-0.002,0.10)$ & 0.06 \\
\hline \multirow[t]{3}{*}{ Patients with no fever treated with rAM } & Control & 4,863 & $82(2 \%)$ & 0 & 0 & \\
\hline & HW & 6,062 & $193(3 \%)$ & $-0.003(-0.02,0.01)$ & $0.002(-0.01,0.01)$ & 0.52 \\
\hline & HWP & 5,984 & $40(1 \%)$ & $0.01(-0.01,0.03)$ & $0.002(-0.01,0.01)$ & 0.73 \\
\hline \multicolumn{7}{|l|}{ RDT uptake } \\
\hline \multirow[t]{3}{*}{ Patients with fever tested with RDT } & Control & 9,297 & $4960(53 \%)$ & 0 & 0 & \\
\hline & HW & 9,825 & $5374(55 \%)$ & $-0.04(-0.15,0.07)$ & $-0.04(-0.20,0.10)$ & 0.57 \\
\hline & HWP & 7,963 & $5153(65 \%)$ & $-0.12(-0.21,-0.03)$ & $-0.02(-0.13,0.09)$ & 0.72 \\
\hline \multirow{3}{*}{$\begin{array}{l}\text { RDT eligible (fever and no obvious alternate diagnosis) } \\
\text { not tested }\end{array}$} & Control & 8,241 & $3697(45 \%)$ & 0 & 0 & \\
\hline & HW & 9,064 & $4000(44 \%)$ & $0.04(-0.07,0.15)$ & $0.06(-0.11,0.23)$ & 0.44 \\
\hline & HWP & 7,292 & $2459(34 \%)$ & $0.12(0.04,0.21)$ & $0.18(0.05,0.32)$ & 0.01 \\
\hline \multirow[t]{3}{*}{ RDT ineligible (no fever) tested } & Control & 4,874 & $587(12 \%)$ & 0 & 0 & \\
\hline & HW & 6,083 & $955(16 \%)$ & $-0.01(-0.07,0.04)$ & $0.01(-0.06,0.07)$ & 0.86 \\
\hline & HWP & 6,000 & $518(9 \%)$ & $0.02(-0.05,0.09)$ & $0.02(-0.04,0.09)$ & 0.43 \\
\hline \multicolumn{7}{|l|}{ Presumptive treatment } \\
\hline \multirow[t]{3}{*}{ RDT eligible treated presumptively for malaria } & Control & 8,241 & $471(6 \%)$ & 0 & 0 & \\
\hline & HW & 9,064 & $374(4 \%)$ & $0.02(-0.01,0.05)$ & $0.01(-0.02,0.04)$ & 0.40 \\
\hline & HWP & 7,292 & $256(4 \%)$ & $0.02(-0.003,0.05)$ & $0.02(-0.004,0.05)$ & 0.09 \\
\hline \multirow[t]{3}{*}{ RDT ineligible treated presumptively for malaria } & Control & 4,874 & $42(1 \%)$ & 0 & 0 & \\
\hline & HW & 6,083 & $47(1 \%)$ & $0.004(-0.001,0.01)$ & $0.003(-0.001,0.01)$ & 0.15 \\
\hline & HWP & 6,000 & $12(0.2 \%)$ & $0.007(0.003,0.01)$ & $0.004(-0.0001,0.01)$ & 0.05 \\
\hline \multicolumn{7}{|l|}{ Adherence to RDT negative } \\
\hline \multirow[t]{3}{*}{ RDT negative receiving AM } & Control & 4,015 & $762(19 \%)$ & 0 & 0 & \\
\hline & HW & 4,539 & $250(6 \%)$ & $0.14(0.08,0.20)$ & $0.10(0.03,0.17)$ & 0.01 \\
\hline & HWP & 4,330 & $189(4 \%)$ & $0.15(0.09,0.21)$ & $0.10(0.04,0.16)$ & 0.002 \\
\hline \multirow[t]{3}{*}{ RDT negative receiving AM (among those with fever) } & Control & 3,488 & $723(21 \%)$ & 0 & 0 & \\
\hline & HW & 3,793 & $235(6 \%)$ & $0.16(0.08,0.23)$ & $0.11(0.03,0.19)$ & 0.01 \\
\hline & HWP & 3,897 & $177(5 \%)$ & $0.21(0.04,0.17)$ & $0.12(0.05,0.19)$ & 0.002 \\
\hline \multirow[t]{3}{*}{ RDT negative receiving AM (among those with no fever) } & Control & 527 & $39(7 \%)$ & 0 & 0 & \\
\hline & HW & 746 & $15(2 \%)$ & $0.05(-0.01,0.10)$ & $0.03(0.010 .05)$ & 0.004 \\
\hline & HWP & 433 & $12(3 \%)$ & $0.04(-0.01,0.10)$ & - & - \\
\hline \multicolumn{7}{|l|}{ Adherence to RDT positive } \\
\hline \multirow[t]{3}{*}{ RDT positive receiving rAM } & Control & 1,455 & $1166(80 \%)$ & 0 & 0 & \\
\hline & HW & 1,696 & $1402(83 \%)$ & $-0.10(-0.35,0.15)$ & $-0.13(-0.45,0.19)$ & 0.39 \\
\hline & HWP & 1,249 & $963(77 \%)$ & $-0.17(-0.41,0.06)$ & $-0.04(-0.25,0.17)$ & 0.69 \\
\hline \multirow[t]{3}{*}{ RDT positive receiving rAM (among those with fever) } & Control & 1,406 & $1149(82 \%)$ & 0 & 0 & \\
\hline & HW & 1,508 & $1255(83 \%)$ & $-0.07(-0.31,0.18)$ & $-0.11(-0.44,0.22)$ & 0.49 \\
\hline & HWP & 1,180 & $942(79 \%)$ & $-0.14(-0.37,0.09)$ & $-0.01(-0.23,0.21)$ & 0.89 \\
\hline \multirow[t]{3}{*}{ RDT positive receiving rAM (among those without fever) } & Control & 49 & $17(35 \%)$ & & & \\
\hline & HW & 188 & $147(78 \%)$ & - & - & \\
\hline & HWP & 69 & $21(30 \%)$ & - & - & \\
\hline
\end{tabular}


Table 5 Effect of interventions on antimalarial prescribing, RDT use and antibiotic prescribing (Continued)

\begin{tabular}{|c|c|c|c|c|c|c|}
\hline \multicolumn{7}{|l|}{ Treatment with antibiotics } \\
\hline \multirow[t]{3}{*}{ Non-malarial illness receiving $A B x$} & Control & 8,942 & $6865(77 \%)$ & 0 & 0 & \\
\hline & HW & 10,118 & $7886(78 \%)$ & $0.01(-0.09,0.12)$ & $0.02(-0.22,0.24)$ & 0.89 \\
\hline & HWP & 10,163 & $7525(74 \%)$ & $0.01(-0.04,0.07)$ & $0.14(-0.01,0.29)$ & 0.06 \\
\hline \multirow[t]{3}{*}{ RDT negative receiving $A B x$} & Control & 4,015 & $2977(74 \%)$ & 0 & 0 & \\
\hline & HW & 4,539 & $3527(78 \%)$ & $-0.02(-0.12,0.09)$ & $0.003(-0.23,0.24)$ & 0.98 \\
\hline & HWP & 4,330 & $3236(75 \%)$ & $-0.004(-0.07,0.06)$ & $0.13(-0.02,0.27)$ & 0.08 \\
\hline \multirow[t]{3}{*}{ RDT eligible receiving $A B x$} & Control & 8,241 & $5731(70 \%)$ & 0 & 0 & \\
\hline & $H W$ & 9,064 & $6808(75 \%)$ & $-0.03(-0.13,0.07)$ & $0.01(-0.21,0.25)$ & 0.89 \\
\hline & HWP & 7,292 & $4,994(68 \%)$ & $0.01(-0.09,0.10)$ & $0.13(-0.03,0.30)$ & 0.09 \\
\hline \multirow[t]{3}{*}{ RDT ineligible receiving $A B x$} & Control & 4,863 & $3774(78 \%)$ & 0 & 0 & \\
\hline & HW & 6,062 & $4531(75 \%)$ & $0.07(-0.07,0.20)$ & $0.03(-0.21,0.28)$ & 0.77 \\
\hline & HWP & 5,984 & 4334 (72\%) & $0.04(-0.02,0.10)$ & $0.15(0.01,0.30)$ & 0.04 \\
\hline
\end{tabular}

\section{Quality of RDT reporting}

Agreement between known RDT results recorded by patient recall and the MTUHA register was high overall $(98 \%$ agreement; kappa $=0.94)$ and in each trial arm. There was also excellent agreement $(\mathrm{kappa}=0.87)$ between RDT results recorded in the MTUHA register and the random selection of RDTs interpreted by a member of the research team. In the final exit survey the sensitivity of the RDT results recorded in MTUHA register against the research blood slides $(n=105)$ was $89 \%$ ( $95 \%$ CI $52 \%$ to $98 \%$ ) and the specificity was $95 \%$ ( $95 \%$ CI $88 \%$ to $98 \%$ ).

\section{Discussion}

Improving the quality of diagnosis at healthcare facilities requires both diagnostic tools and behaviour change of longstanding prescriber behaviour. Introducing RDTs for malaria with basic training has had some effect, but in multiple studies does not get close to zero overdiagnosis [11-16]. Fever is the commonest reason for patients presenting to clinics in Africa, and malaria the commonest diagnosis made, so even modest changes in overdiagnosis can have substantial impact on patient management and overuse of antimalarials. This large trial of behavioural interventions at the prescriber level led to a significant reduction in over-prescription but a patientoriented intervention did not lead to further significant gains. The interventions led to a high level of adherence to results, and showed that with this combination of simple and repeatable behavioural interventions overdiagnosis of malaria could be reduced to close to zero in an area where the great majority of antimalarials used to be prescribed to people with no parasites. Near zero overdiagnosis brings considerable gains that will become increasingly important if resistance to ACTs spreads as infections occurring in the weeks following unnecessary treatment may be exposed to sub-therapeutic drug levels, particularly relevant to the longer acting ACT partner drugs such as piperaquine. In addition it allows improved diagnosis of other diseases and increases the reliability of routine data to be used to monitor malaria control.

Most studies of antimalarial drug prescribing in Tanzania and elsewhere have shown that prescribing antimalarial drugs even when presented with evidence of a non-malarial cause of fever, is a normalised and expected practice, reinforced by malaria-oriented infrastructure and disease control activities [31-33]. An important finding from the early phase of the trial is that the introduction of RDTs supported by the standard RDT training package in Tanzania was followed by a three to four fold reduction in antimalarial drug prescription in all trial arms. That prescribers changed their practice so quickly, and to the extent of almost eliminating use of antimalarial drugs for non-malarial cases in the intervention arms can be interpreted in the context of an increasing national drive for parasite-based malaria diagnosis, with a country-wide scale-up of RDTs that has been ongoing since 2010 [34] which could have raised awareness and readiness for change [35]. The additional benefit in the intervention arms may be attributed to the intervention's emphasis on changing practice through a shared experience of the process of change; such a process has been described as using a 'community of 
practice' [36]. It could also be that the quality of delivery of the standard training in our trial may have been greater because trainers were incentivised by the study, which would point to the importance, noted by others, of the way interventions are delivered as much as the content [37].

The largest effect we observed was the improvement in adherence to RDT negative results in the health worker arm, with further marginal gains in the health worker-patient arm. This was a specific practice targeted for change by the interventions. However, while adherence to RDT negative results improved, prescribing of ACT to RDT positives was lower than we would have liked for improved malaria case management. This did not appear to be related to ACT stock-outs. Future interventions need to ensure that attention is focused on correct treatment of non-malarial febrile illnesses for which there are currently no routinely used point of care diagnostic tests in Africa. Our estimate of effect was based on a case definition of malaria that included a current or recent fever and yet over one fifth of patients who were tested without such a history actually had a positive RDT. While this may in part be due to persistence of HRP-2 a case could be made to treat these patients, particularly where malaria elimination is the goal.

The peer group workshops, the feedback SMS and the motivational SMS each appear to have contributed incremental improvements to the point where overuse of antimalarials was nearly eliminated after the maximum intervention was received. The small-group training was a strategy borrowed from resource-rich environments where physicians often participate in support groups to reflect on, and support change in their clinical and consultation skills. It builds on the finding that perceived peer pressure is one of the reasons for malaria misdiagnosis [32] and the observation that change in RDT use has occurred through informal group discussion and experimentation [38]. Formalising such a process of change requires skilled facilitators and success requires motivated health workers. These elements are often not present in resource poor settings, but our results do suggest that a measurable improvement is possible with only three attendances, which is achievable. As such, peer group training may provide a future model for inservice education beyond malaria case management, and may be useful to employ, for example, as medical practice moves from a scenario of simple guidelines with few diagnostic resources to a scenario where a wider range of diagnoses are considered and supported by more diagnostic resources. The sending of SMS to prescribers appears a low cost addition, as has been found elsewhere, although their effect in the absence of the initial training programmes cannot be established from these trials [27]. The intervention in which prescribers received patient leaflets and clinic posters as well as the interactive workshops is low cost to scale-up but it did require intensive development and pretesting with end users, and while only marginal improvements in prescribing beyond the workshops alone were observed we did observe continued improvements in the selection of patients for RDT testing. Further research would be required to establish the independent effects of each intervention component. For programme managers, achieving improved targeting of antimalarials will require a balance between the level of overuse of antimalarials they are willing to tolerate, and the level of investment in interventions they are able to make.

In our study, the pre-trial levels of antibiotic prescribing were already high, exceeding two-thirds of consultations, and this increased further following the introduction of RDTs, although prescribing was significantly lower in the prescriber and patient arm. A general increase in antibiotic prescribing has been found in other studies of the impact of RDTs on prescriber behaviour [13,39]. There is evidence that less than $10 \%$ of patients with suspected malaria and a negative RDT result has a positive blood culture, and the commonest indication for antibiotics appears to be the WHO-IMCI category of 'non-severe pneumonia', an indication for which a placebo controlled trial failed to demonstrate a benefit [40]. These considerations suggest the need to more clearly define indications for antibiotics in RDT negative patients with suspected malaria. Currently, there is a suggestion of some degree of substituting antimalarials for antibiotics.

Trials of behavioural interventions often suffer from a lack of sufficient formative qualitative research; a strength of the current study was an in-depth formative period. A novel feature of the trial was targeting prescribers and patients (who may influence prescribers) simultaneously. However, the study has a number of limitations in common with all trials of complex interventions. This was an intervention with multiple components and the study was not designed to distinguish their independent effects. In addition, we cannot exclude that our results are subject to participation bias, whereby behavioural outcomes can change due to evaluation activities in all arms of the study [41]. The observation of patient care can affect performance of health staff (the 'Hawthorne Effect'), although prolonged observation reduces this effect, and was similar in all three arms all of whom had received training in RDTs so would be unlikely to be the cause for the significant effect seen. We also found no major differences in prescribers' practices on days when there was an exit survey compared with days when there was none (Leurent et al., unpublished data). Finally, the proximity of facilities in different arms 
may have allowed some leakage of effect between arms, but this would tend to reduce effect sizes. The trial findings are likely to be generalisable to similar settings, the rural or semi-rural primary care facilities that serve much of sub-Saharan Africa.

\section{Conclusions}

In a geographical area where previously in some areas over $90 \%$ of patients who were prescribed an antimalarial did not have malaria, this study has demonstrated that a combination of prescriber and patient behavioural interventions can, by incremental steps, take this down close to zero. The large reduction in antimalarial drug prescribing that occurred in both the control and intervention arms suggests that introducing RDTs with standard training at the primary care level is likely to have a significant impact on the overuse of ACT in primary care facilities in Africa. In addition, small group training with SMS messaging was associated with a significant and sustained improvement in prescriber adherence to RDT results. These interventions may become increasingly important as health services develop and clinical staff are required to use a wider range of diagnostic tests and treatment options for the commonest syndrome presenting to clinicians in Africa.

\section{Additional files}

\section{Additional file 1: Effect of interventions on recommended antimalarial prescribing among patients visiting facilities when there were no RDT or AL stock-outs. \\ Additional file 2: Effect of interventions on recommended antimalarial prescribing among patients in consultation with prescriber who attended training.}

Additional file 3: Effect of interventions on secondary outcomes among patients visiting facilities during no RDT and/or AL stock-outs.

\section{Abbreviations \\ Abx: antibiotics; ACT: artemisinin combination therapy; ALu: Artemether lumefantrine; AM: any antimalarial; aRD: adjusted risk difference; $\mathrm{Cl}$ : confidence interval; HRP-2: histidine-rich protein II; HW: health worker intervention arm; HWP: health worker-patient-oriented intervention arm; NMCP: National Malaria Control Programme; rAM: recommended antimalarial; RD: risk difference; RDT: rapid diagnostic test; SD: standard deviation; SMS: mobile phone text messages.}

\section{Competing interests}

The authors declare that they have no competing interests.

\section{Authors' contributions}

CJMW and HR secured funding and conceived the study. BC, HM, CIRC, GM, $F M u, R M, R O, C J M W$, and HR designed the study. CIRC and AW designed the intervention and data collection tools. EF trained the facilitators. HM and HR implemented the study. BC, HM, GM, and RMw were responsible for data collection and monitoring. BC, FMt, and RMw were responsible for data management and cleaning. BC and FMt analysed the data. BC, CIRC, CJMW, and HR interpreted the data. BC and HR wrote the first draft of the manuscript with contribution from CIRC and CJMW. All authors read and approved the final manuscript.

\section{Acknowledgements}

We are grateful to the staff of the health facilities and the patients for their participation in the study. We also wish to thank the trainers of staff in the intervention arms: Harry Mwerinde, Sia Msuya and Oscar Mafole. We thank Prof Alison Grant and other members of the data safety monitoring board for their advice and approval of the statistical analysis plan.

\section{Funding}

The study was funded by the ACT Consortium through a grant from the Bill \& Melinda Gates Foundation to the London School of Hygiene \& Tropical Medicine. The funders had no role in the design, data collection and analysis, decision to publish or preparation of the manuscript.

\section{Author details}

${ }^{1}$ Faculty of Epidemiology and Population Health, London School of Hygiene and Tropical Medicine, Keppel St, London WCIE 7HT, UK. ${ }^{2}$ Joint Malaria Programme, Kilimanjaro Christian Medical Centre, Box 2228, Moshi, Tanzania. ${ }^{3}$ Faculty of Public Health and Policy, London School of Hygiene and Tropical Medicine, Keppel St, London WCIE 7HT, UK. ${ }^{4}$ National Institute for Medical Research, Amani Centre, Tanga, Tanzania. ${ }^{5}$ Wellsense International Public Health Consultants, P.O. Box 788, Kilifi, Kenya. ${ }^{6}$ National Malaria Control Programme, Ministry of Health and Social Welfare, Ocean Road, Dar es Salaam, Tanzania. ${ }^{7}$ Faculty of Infectious and Tropical Diseases, London School of Hygiene and Tropical Medicine, Keppel St, London WCIE 7HT, UK.

Received: 21 November 2014 Accepted: 13 April 2015

Published online: 15 May 2015

\section{References}

1. Amexo M, Tolhurst R, Barnish G, Bates I. Malaria misdiagnosis: effects on the poor and vulnerable. Lancet. 2004;364:1896-8.

2. Leslie T, Mikhail A, Mayan I, Anwar M, Bakhtash S, Nader M, et al. Overdiagnosis and mistreatment of malaria among febrile patients at primary healthcare level in Afghanistan: observational study. BMJ. 2012;345:e4389.

3. Reyburn H, Mbatia R, Drakeley C, Carneiro I, Mwakasungula E, Mwerinde O, et al. Overdiagnosis of malaria in patients with severe febrile illness in Tanzania: a prospective study. BMJ. 2004;329:1212.

4. Dondorp AM, Yeung S, White L, Nguon C, Day NP, Socheat D, et al. Artemisinin resistance: current status and scenarios for containment. Nat Rev Microbiol. 2010;8:272-80.

5. D'Acremont V, Lengeler C, Genton B. Reduction in the proportion of fevers associated with Plasmodium falciparum parasitaemia in Africa: a systematic review. Malar J. 2010;9:240.

6. D'Acremont V, Lengeler C, Mshinda H, Mtasiwa D, Tanner M, Genton B. Time to move from presumptive malaria treatment to laboratory-confirmed diagnosis and treatment in African children with fever. PLoS Med. 2009;6:e252.

7. WHO. Guidelines for the treatment of malaria. WHO/HTM/MAL/2006.1108; 2006: p. 10.

8. WHO. Guidelines for the treatment of malaria. 2nd ed. 2010

9. WHO. World Malaria Report. 2013. ISBN 9789241564694.

10. Barat L, Chipipa J, Kolczak M, Sukwa T. Does the availability of blood slide microscopy for malaria at health centers improve the management of persons with fever in Zambia? Am J Trop Med Hyg. 1999;60:1024-30.

11. Reyburn $H$, Mbakilwa $H$, Mwangi $R$, Mwerinde O, Olomi R, Drakeley $C$, et al. Rapid diagnostic tests compared with malaria microscopy for guiding outpatient treatment of febrile illness in Tanzania: randomised trial. BMJ. 2007;334:403.

12. Bisoffi Z, Sirima BS, Angheben A, Lodesani C, Gobbi F, Tinto H, et al. Rapid malaria diagnostic tests vs. clinical management of malaria in rural Burkina Faso: safety and effect on clinical decisions. A randomized trial. Trop Med Int Health. 2009;14:491-8.

13. D'Acremont V, Kahama-Maro J, Swai N, Mtasiwa D, Genton B, Lengeler C. Reduction of anti-malarial consumption after rapid diagnostic tests implementation in Dar es Salaam: a before-after and cluster randomized controlled study. Malar J. 2011;10:107.

14. Hamer DH, Ndhlovu M, Zurovac D, Fox M, Yeboah-Antwi K, Chanda P, et al. Improved diagnostic testing and malaria treatment practices in Zambia. JAMA. 2007;297:2227-31. 
15. Ansah EK, Narh-Bana S, Epokor M, Akanpigbiam S, Quartey AA, Gyapong J, et al. Rapid testing for malaria in settings where microscopy is available and peripheral clinics where only presumptive treatment is available: a randomised controlled trial in Ghana. BMJ. 2010;340:c930.

16. Leslie T, Mikhail A, Mayan I, Cundill B, Anwar M, Bakhtash SH, et al. Rapid diagnostic tests to improve treatment of malaria and other febrile illnesses: patient randomised effectiveness trial in primary care clinics in Afghanistan. BMJ. 2014;348:g3730.

17. Lubell $Y$, Reyburn H, Mbakilwa H, Mwangi R, Chonya S, Whitty CJ, et al. The impact of response to the results of diagnostic tests for malaria: cost-benefit analysis. BMJ. 2008;336:202-5.

18. Chandler Cl, Mangham L, Njei AN, Achonduh O, Mbacham WF, Wiseman V. 'As a clinician, you are not managing lab results, you are managing the patient': how the enactment of malaria at health facilities in Cameroon compares with new $\mathrm{WHO}$ guidelines for the use of malaria tests. Soc Sci Med. 2012;74:1528-35

19. Chandler Cl, Meta J, Ponzo C, Nasuwa F, Kessy J, Mbakilwa H, et al. The development of effective behaviour change interventions to support the use of malaria rapid diagnostic tests by Tanzanian clinicians. Implement Sci. 2014;9:83.

20. Mtove G, Amos B, Nadjm B, Hendriksen IC, Dondorp AM, Mwambuli A, et al. Decreasing incidence of severe malaria and community-acquired bacteraemia among hospitalized children in Muheza, north-eastern Tanzania, 2006-2010. Malar J. 2011;10:320

21. Mwanziva C, Shekalaghe S, Ndaro A, Mengerink B, Megiroo S, Mosha F, et al. Overuse of artemisinin-combination therapy in Mto wa Mbu (river of mosquitoes), an area misinterpreted as high endemic for malaria. Malar J. 2008;7:232.

22. Hayes RJ, Moulton LH. Cluster randomised trials. Taylor \& Francis Group: Chapman and Hall/CRC; 2009.

23. Moulton LH. Covariate-based constrained randomization of grouprandomized trials. Clin Trials. 2004;1:297-305.

24. Nietert PJ, Jenkins RG, Nemeth LS, Ornstein SM. An application of a modified constrained randomization process to a practice-based cluster randomized trial to improve colorectal cancer screening. Contemp Clin Trials. 2009:30:129-32.

25. Sismanidis C, Moulton LH, Ayles H, Fielding K, Schaap A, Beyers N, et al. Restricted randomization of ZAMSTAR: a $2 \times 2$ factorial cluster randomized trial. Clin Trials. 2008;5:316-27.

26. NMCP. Training guide and facilitators manual for malaria rapid diagnostic tests, Malaria control series 26. Tanzania: Ministry of Health and Social Welfare; 2010

27. Zurovac D, Sudoi RK, Akhwale WS, Ndiritu M, Hamer DH, Rowe AK, et al. The effect of mobile phone text-message reminders on Kenyan health workers' adherence to malaria treatment guidelines: a cluster randomised trial. Lancet. 2011;378:795-803.

28. Hayes RJ, Bennett S. Simple sample size calculation for cluster-randomized trials. Int J Epidemiol. 1999;28:319-26.

29. Hopkins H, Bebell L, Kambale W, Dokomajilar C, Rosenthal PJ, Dorsey G. Rapid diagnostic tests for malaria at sites of varying transmission intensity in Uganda. J Infect Dis. 2008;197:510-8.

30. Laurent A, Schellenberg J, Shirima K, Ketende SC, Alonso PL, Mshinda H, et al. Performance of HRP-2 based rapid diagnostic test for malaria and its variation with age in an area of intense malaria transmission in southern Tanzania. Malar J. 2010;9:294

31. Chandler Cl, Chonya S, Boniface G, Juma K, Reyburn H, Whitty CJ. The importance of context in malaria diagnosis and treatment decisions - a quantitative analysis of observed clinical encounters in Tanzania. Trop Med Int Health. 2008;13:1131-42

32. Chandler $\mathrm{Cl}$, Jones C, Boniface G, Juma K, Reyburn H, Whitty CJ. Guidelines and mindlines: why do clinical staff over-diagnose malaria in Tanzania? A qualitative study. Malar J. 2008;7:53.

33. Chandler Cl, Mwangi R, Mbakilwa H, Olomi R, Whitty CJ, Reyburn H. Malaria overdiagnosis: is patient pressure the problem? Health Policy Plan. 2008;23:170-8.

34. NMCP. National guidelines for diagnosis and treatment of malaria. Malaria control series 25. Dar es Salaam. Tanzania: Ministry of Health and Social Welfare; 2011

35. Woodward C. Improving provider skills: strategies for assisting health workers to modify and improve skills: developing quality health care - a process of change. In: Evidence and Information for Policy. Geneva:
Department of Organization of Health Services Delivery, World Health Organisation; 2000.

36. Wenger E. Communities of practice. Learning, meaning, and identity. New York: Cambridge University Press; 1998.

37. Michie S, Fixsen D, Grimshaw JM, Eccles MP. Specifying and reporting complex behaviour change interventions: the need for a scientific method. Implement Sci. 2009;4:40.

38. Chandler $\mathrm{Cl}$, Whitty CJ, Ansah EK. How can malaria rapid diagnostic tests achieve their potential? A qualitative study of a trial at health facilities in Ghana. Malar J. 2010;9:95

39. Yeboah-Antwi K, Pilingana P, Macleod WB, Semrau K, Siazeele K, Kalesha P, et al. Community case management of fever due to malaria and pneumonia in children under five in Zambia: a cluster randomized controlled trial. PLoS Med. 2010;7:e1000340

40. Hazir T, Nisar YB, Abbasi S, Ashraf YP, Khurshid J, Tariq P, et al. Comparison of oral amoxicillin with placebo for the treatment of world health organization-defined nonsevere pneumonia in children aged 2-59 months: a multicenter, double-blind, randomized, placebo-controlled trial in pakistan. Clin Infect Dis. 2011;52:293-300.

41. McCambridge J, Kypri K, Elbourne D. In randomization we trust? There are overlooked problems in experimenting with people in behavioral intervention trials. J Clin Epidemiol. 2014;67:247-53.

42. Rutstein $\mathrm{S}$, Johnson $\mathrm{K}$. The DHS wealth index. DHS comparative reports no.6. Calverton, Maryland: ORC Macro, 2004: Chapter 2: Construction of the DHS wealth index: page 8-14.

43. Vyas S, Kumaranayake L. Constructing socio-economic status indices: how to use principal components analysis. Health Policy Plan. 2006;21:459-68.33.

\section{Submit your next manuscript to BioMed Central and take full advantage of:}

- Convenient online submission

- Thorough peer review

- No space constraints or color figure charges

- Immediate publication on acceptance

- Inclusion in PubMed, CAS, Scopus and Google Scholar

- Research which is freely available for redistribution 